\title{
Analysis of Financial Distress cross Countries: Using Macroeconomic, Industrial indicators and Accounting Data
}

\begin{abstract}
This paper applies three-way multidimensional scaling and cluster analysis to examine the nature of insolvency in the Gulf Corporation Council, the United Kingdom and the United States of America between from 2004 to 2012. The findings of this paper reveal that analyzing the financial statements data with indicators of industrial and macroeconomic, provide a better understanding of the performance of the solvent and insolvent firms cross-counties. The results proved that the financial health of firms should be examined in situ within the local macro environment. There is also a clear implication for managers of firms as paying most of ones attention to one aspect of financial performance appears to increase the risk of insolvency.

Keywords: Corporate insolvency, Financial ratios, Macroeconomic indicators and Multidimensional scaling
\end{abstract}

\section{Introduction}

Financial distress is one of the most important threats facing firms regardless of their size and operation (Charitou et al. 2004). In the last four decades, predicting financial distress research has been a hot topic in corporate finance for 5 academics and practitioners as it serves as an effective early warning signal for creditors, investors, corporate regulators and other stakeholders. The collapse of many global firms during the financial crisis of 2007, proved the limitation of corporate distress models based only on observables at the firm level as there is an urgent need to examine the dynamic macro environment (Tinocoa and 

N., 2018, 2013). Furthermore, changing of government regulation targeting a specific product, such as has happened with tobacco, is another factor that can potentially increase the bankruptcy rate for the firms in specific industry.

It seems reasonable to suggest that, to better understand corporate failure, we should study the effects of all information accounting, macroeconomic and industry information simultaneously; i.e. adopt a multilevel perspective (Kozlowski and Klein, 2000). However, most corporate failure studies are not multi-level (Goudie and Meeks, 1991), as researchers tend to study each level discretely. The majority of studies are at the firm-level where, typically, researchers study the effects of within-firm factors within a single country while controlling for industrial-level effects by, for example, matching firms by industry sector (see (Altman and Narayanan, 1997)). Likewise, at the macro-level, studies tend to focus on the variance of macro-level variables within a single country over time.

Therefore, the aim of the current study is to discover whether new indicators macroeconomic and industrial information can give a better understanding of characterising insolvency in different macro dynamic environments by using three-way multidimensional scaling (MDS) and cluster analysis. This study contributes to the literature in three ways. First, while the majority of studies focus on analysis of the financial ratios to predict the corporate insolvency, so our study adds a new dimension by taking into account macroeconomic and industrial information which has been accorded limited attention in previous corporate insolvency researches. This information allows us to examine how specific aspects of the macro environment may impact firm failure. We believe that the impact of analysis related to the combination of such external pressure data as well as accounting data on firms is of direct interest, especially since it is recognized that not all companies respond to external pressures equally. Second, one of the crucial contributions of this study is that many researchers have studied corporate insolvency in the course of individual studies of each country. In light of the added value of investigating the determinants of corporate failure 40 across different contexts, this study adds to the existing literature a new pattern 
of studying the similarities and dissimilarities of the structures of insolvent and solvent firms contextual with other firms in different economies like the Gulf Corporation Council (GCC), the United Kingdom (UK) and the United States of America (USA). Third, our study is among few studies that adopt the MDS

45 model in the field of corporate insolvency. To the best of our knowledge, there is no study that applies the MDS model in different regions.

The remainder of this paper is organized as follows: Section 2 discusses the literature on the different levels of study related to corporate insolvency research, states the research questions, describes the sample and summary statistics and provides the analysis and discussion of the empirical test and finding in Section 3. This is followed by the final conclusions and discussing the implications of the results in Section 4.

\section{Literature and research questions}

\subsection{Financial ratios}

The majority of financial distress research focuses on the impact of withinfirm factors. Typically, researchers use financial ratios as proxies for the financial management of the firm. Altman (1968), Deakin (1972), Ohlson (1980), Zmijewski (1984), Gilbert et al. (1990) reported profitability and leverage ratios as significant. Similarly, researchers such as Beaver (1966), Altman (1968), 60 Deakin (1972), Peel et al. (1986), Back et al. (1996) and Jones and Hensher (2004) reported liquidity ratios as significant. Although early research tended to ignore them, cash flow-based ratios have also demonstrated predictive capacity in a number of studies, such as those of Gilbert et al. (1990), Sung et al. (1999) and Ravisankar et al. (2010). In contrast, although both types appeared 65 in Altman (1968)'s seminal study, neither activity nor market ratios have been widely reported as significant, bar a few exceptions, such as Peel et al. (1986) who reported activity ratios to be significant.

There is no doubt, then, that financial ratios are an important aspect of insolvency research, but what we learn about insolvency from each study de- 
pends on how the researchers approached the problem and the techniques they used. Some methods offer more insight than others. As computing power and „speed have grown, machine-learning techniques, such as neural networks (Coats and Fant, 1993 ; Salchenberger et al. 1992) and genetic algorithms (Shin and Lee, 2002; Varetto, 1998), have become more popular because they can classify

75 insolvent and solvent firms very accurately. However, they are not interpretable and, as such, offer no insight. In this regard, the more traditional statistical techniques, such as Logit regression (Ohlson, 1980, Peel et al., 1986, Zavgren, 1985), Probit regression (Zmijewski, 1984), univariate analysis (Beaver, 1966 , Deakin, 1972) and, to a lesser extent, Multiple Discriminant Analysis (MDA)

${ }_{80}$ Altman, 1968, Sung et al., 1999), are more useful because one can interpret the results. Unfortunately, statistical techniques are not without some limitations themselves. MDA, often the default baseline technique for evaluating other techniques (Altman and Narayanan, 1997), assumes that financial ratios are normally distributed and that the variance-covariance structures of insolvent and solvent firms are equivalent, but, as Ezzamel et al. (1987) show, both of these assumptions rarely hold up in practice. Logit and Probit regression models do not have the distributional assumptions of MDA, but both are prone to producing biased estimates, particularly in small-sample studies (Firth, 1993), which are quite common in insolvency studies. Given these problems, Molinero and 90 Ezzamel, 1991) suggest MDS as an alternative. A non-parametric technique, MDS has no distributional assumptions unlike MDA. MDS is also not reliant on maximum likelihood estimates and, as a result, does not suffer from biases found in Logit and Probit regression. Furthermore, the visualisation philosophy of MDS allows for a richer, more intuitive insight into corporate insolvency.

${ }_{95}$ Perhaps because of the precedent set by pioneers Beaver (1966) and Altman (1968), most micro-level research of insolvency is empirical rather than theoretical. Even so, a number of theories have been used or proposed to explain insolvency at the firm level. One stream of research applies Entropy theory, based on changes in the structure of the balance sheets of firms, to predict failure (Booth, 1983). A second stream applies the Gamblers ruin theory in which 
researchers posit that a failing firm will sell its assets to meet its losses until its net worth is zero: i.e. it is bankrupt (Morris, 1997, Scott, 1981). A third, much more popular stream applies the cash management theory, which suggests persistent cash flow problems will eventually cause firm distress Gombola and

105 Ketz, 1983b; A. Aziz and Lawson, 1988, Aziz and Lawson, 1989, Gilbert et al. 1990).

\subsection{Macroeconomic indicators}

Macroeconomic indicators, Liu (2004) claimed, have been neglected in the (largely) microeconomic analysis of corporate insolvency. Nevertheless, a number of macroeconomic factors have been found to affect insolvency. One such factor is the rate of inflation. Wadhwani (1986) suggested that inflation can create cash flow problems and cause bankruptcy; this is because imperfect credit markets fail to regulate debt levels with inflation. Similarly, interest rates have been shown to impact failure rates in a number of countries, such as the US 115 Rose et al. (1982) and the UK Desai and Montes (1982), and Young (1995). Oil prices may also be a relevant macroeconomic indicator, particularly in the GCC, where the oil and gas industries are prevalent. Platt et al. (1994) found that adding oil prices as an independent predictor increased the classification accuracy of their prediction model.

\subsection{Industrial factors}

Often, conditions across industry sectors can be, or appear to be, so disparate that it is common for investors to diversify their investments across a number of industry sectors in an attempt to minimise industry-specific risk of insolvency (see Fabozzi et al. (2002)). Using standard econometric analysis, Caves (1998) reports global patterns that suggest business failure rates differ across industry sectors. Based on this premise, typically, to control for industry-specific effects, insolvency studies match each insolvent firm sampled with its nearest neighbour among the population of continuing firms in the same industry Altman and Narayanan, 1997; Kumar and Ravi, 2007). A second, more refined way to 

median (Platt and Platt, 1991).

Since the majority of studies do not explicitly model the effect of industry sector, the evidence for how insolvency varies across different industries or how specific industry characteristics may impact insolvency is relatively sparse, although there are some exceptions to this general pattern. An early example is the study of (Gupta and Huefner, 1972), which examined cluster patterns in financial ratios across different industry sectors. However, the effect of industry sector differences on corporate insolvency may be insignificant, as reported recently by Hossari (2009).

Another factor that can impact corporate insolvency is legislation, particularly bankruptcy codes. Differences in insolvency rates have been observed before and after legislation within and across countries. Bhattacharjee et al. (2004) reported that the impact of macroeconomic instability on bankruptcy is less marked in the United States than in the United Kingdom because USA firms facing bankruptcy are shielded from economic instability by Chapter 11. Beyond bankruptcy codes, other regulations had been shown to significantly impact insolvency. For example, Campbell et al. (2012) claimed that the size of the state government affected differences in failure rates across states in the United States.

\subsection{A multilevel perspective on financial distress}

The foregoing literature review suggests that insolvency is likely to be a multilevel phenomenon, as, conceptually, there are clear cross-level links among the factors, which are believed to be significant. For example, micro-level research suggests that insolvency can be predicted by profitability, leverage, liquidity and

cash flow-based financial ratios. Hence, we can infer that any factor outside the firm, for example, a macroeconomic condition that can affect earnings, debt, equity or cash generation, will probably affect the risk of insolvency. Despite all this, only a few insolvency studies have taken a multilevel perspective.

In this regard, Goudie and Meeks (1991) and Bhattacharjee et al. (2004) 


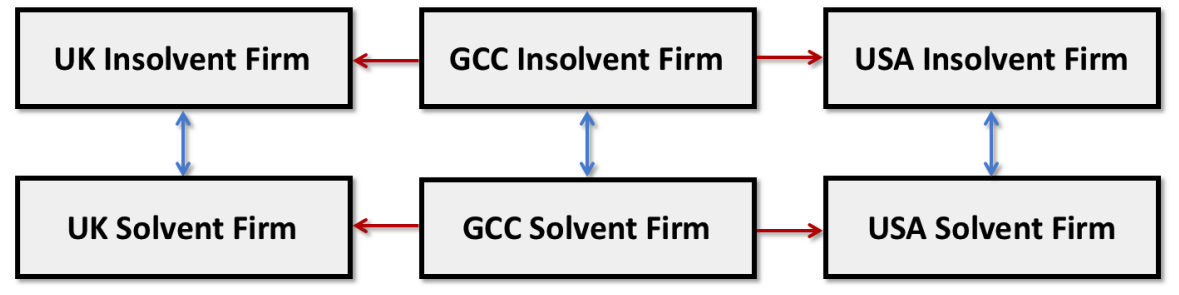

Figure 1 GCC insolvency vis-a-vis other regions: framework of comparisons.

are exceptional; they are among the few to have modelled insolvency taking a multilevel perspective. Goudie and Meeks (1991) predicted firm failure, taking into account macroeconomic-, industry- and firm-level effects. They used a two-stage approach: firstly, they predicted each companys financial accounts using a Keynesian economic model-the macro-industry model (MDM); they then predicted the companys insolvency using multivariate discriminant analysis based on the predicted accounts. Hossari (2009) applied multilevel modelling (MLM) to examine the effect of the industry sector on the risk of insolvency among Australian firms using financial ratios. Bhattacharjee et al. (2004) used macroeconomic variables, industry-effects and firm-level factors as inputs into

a Cox Proportional Hazards model to examine the effect of macroeconomic instability and the insolvency legislation in the United States and the United Kingdom.

\subsection{The research problem: contextualizing the nature of insolvency in the GCC}

The majority of insolvency studies to date have used samples from the USA, followed by the UK and other European countries (Kumar and Ravi, 2007). Despite a number of recent studies using samples from elsewhere, such as Australia (Booth, 1983), and France (Mselmi et al., 2017), insolvency research in the GCC remains underdeveloped in comparison.

Notably, Khoja et al. (2014) found that, in the GCC, insolvent firms appear to focus much more on non- strategic sales activities than solvent firms, but having only sampled firms in the GCC, they were not able to state whether the 
differences were due to the intrinsic differences between failing and healthy firms, as opposed to the prevailing environment in the GCC, which is quite different from other regions. As (Khoja et al. 2014, p. 4) admit, there are important differences between the GCC and other major trading blocs. These include the GCC economies dependency on oil and the GCC stock markets being less mature and liberal and inefficient in the weak form (AlAjmi and Kim, 2012, Arouri et al. 2011).

In this study, we examine a number of research questions based on the framework of comparisons shown in figure 1. The first and second of the research questions arise from horizontal comparisons:

RQ1: In what way are the financial structures of healthy firms in the GCC similar to those in the UK and the USA?

RQ2: In what way are the financial structures of insolvent firms in the GCC similar to those in the UK and the USA?

RQ1 and RQ2 both address the notion of universal firm characteristics. Whereas RQ1 considers whether a solvent firm in the GCC has distinctive characteristics that would be readily recognised as those of a solvent firm elsewhere (such as in the UK and the USA), RQ2 considers the idea that insolvent firms in the GCC share identifiable characteristics with insolvent firms in other regions. In contrast, the third research question, RQ3, arises from the vertical following of from horizontal comparisons in Figure 1.

It addresses the idea of universal solvent versus insolvent differences and considers whether differences observed between solvent and insolvent firms in the GCC would be readily observed between solvent and insolvent firms elsewhere, say in the UK or the USA. In other words, do the characteristics that differentiate a failing firm from a healthy one in the GCC remain unchanged elsewhere?

RQ3: In what way are the differences observed between solvent and insolvent firms in the GCC similar to the differences observed between solvent and insolvent firms in the USA and the UK?

The multilevel perspective should enable us to understand how macroeco- 
nomic factors may be related to the factors that may define or influence the character of insolvency in the GCC and whether comparable patterns can be expected elsewhere. Hence the fourth research question, RQ4, is the following:

RQ4: How are macroeconomic factors related to characteristics that typify insolvency in the GCC, and are the relationships comparable in the USA and $U K$ ?

The USA and UK are ideal comparators for contextualising insolvency in the GCC for two reasons, Firstly, while little is known about insolvency in the GCC, arguably, given the larger body of research using samples from the USA and the UK (Kumar and Ravi, 2007), nowhere else is insolvency better understood than in those countries. The UKs and USAs environments contrast sharply with the GCC. Relative to the GCC, the UK and USA stock markets are more mature, 225 more efficient in the weak form and more liberal AlAjmi and Kim, 2012, Arouri et al. 2011). Both countries economies are also less dependent on oil and, hence, less sensitive to oil prices. Furthermore, while similar to each other, the UK and the USA also differ from each other in important ways, as they are geographically distant and belong to different economic blocs, The UK is in the European Union, while the USA is in the North American Free Trade Agreement. They also have different legislations (see, for example, Bhattacharjee et al. (2004)). Hence, comparing the GCC to each country should give unique insights.

Secondly, on the trade side, the USA and the UK have formed important investment and trade partnerships with the GCC, creating a high-level investment which has reached $7.2 \%$ investment growth, compared to $2 \%$ growth in the rest of the world. Large European and USA banks have set up in the GCC region, and many other projects have long been attractive to Western firms in other industries, especially in the petroleum and real estate sectors. Thus, this region is considered to be a promising business environment for Western firms, especially with the GCC governments efforts to develop the liberalization of foreign investment laws and to increase foreign ownership in the GCC stock market. Thus, the Western and USA companies investment in the GCC market may experience different business environments as well as variance of the 
commercial risks, which can be reduced by understanding and determining the main corporate failure factors. These could be different from the predictors of bankruptcy in the Western countries.

\section{Data, analysis and results}

\subsection{Data}

\subsubsection{Sample of firms}

We collected data on matched pairs of insolvent and solvent firms in the GCC, the UK and the USA during the period of 2004 to 2012. To operationalise our main goal, which was to contextualise insolvency in the GCC using the UK and USA as comparators, we had to make like-for-like comparisons by holding important properties of firms constant across the different environments.

255 Therefore, we categorised insolvency in the same way across the three countries by applying the Kuwaiti legal definition of insolvency, which defines a firm as insolvent when its accumulated losses reach $25 \%$ of its capital.

We matched each insolvent firm with an equivalent solvent firm in the same country by industry sector and by comparable asset size. These matching priteria are those which are most widely used in the literature Altman and Narayanan, 1997). For each pair of firms, we collected the financial data for the year prior to failure. For the GCC and the UK, we managed to find 58 matching pairs of firms, but we found only 49 pairs for the USA due to the small number of insolvent firms in the Agriculture and Hotel and Tourism sectors. The sample of firms is displayed by sector and country in Table 1 .

\subsubsection{Measures of within-firm conditions: financial ratios}

To measure conditions at the firm level, we collected the financial statements of the firms from the database DataStream ${ }^{\mathrm{TM}}$ as well as from the firms' own websites, and we used the financial statements to calculate the financial ratios. To be consistent with Khoja et al. (2014), we calculated the 28 financial ratios that have been most widely and successfully used in the literature Altman, 
Table 1

Sample of insolvent/solvent firms by sector and country

\begin{tabular}{|c|c|c|c|c|}
\hline \multicolumn{5}{|c|}{ Sample of Insolvent Firms: Sector by Country } \\
\hline \multirow[b]{2}{*}{ Sectors } & \multicolumn{3}{|c|}{ Country } & \multirow[b]{2}{*}{ Total } \\
\hline & GCC & UK & $\mathrm{USA}$ & \\
\hline Agriculture & 15 & 15 & 7 & 37 \\
\hline Construction & 7 & 7 & 7 & 21 \\
\hline Hotel and Tourism & 5 & 5 & 4 & 14 \\
\hline Industrial Investment & 9 & 9 & 9 & 27 \\
\hline Petrochemical Industries & 3 & 3 & 3 & 9 \\
\hline Retail and Services & 12 & 12 & 12 & 36 \\
\hline Telecommunications & 1 & 1 & 1 & 3 \\
\hline Transportation & 6 & 6 & 6 & 18 \\
\hline Total & 58 & 58 & 49 & 165 \\
\hline \multicolumn{5}{|c|}{ Sample of Solvent Firms: Sector by Country } \\
\hline & \multicolumn{3}{|c|}{ Country } & \\
\hline Sectors & GCC & $\mathrm{UK}$ & $\mathrm{USA}$ & Total \\
\hline Agriculture & 15 & 15 & 7 & 37 \\
\hline Construction & 7 & 7 & 7 & 21 \\
\hline Hotel and Tourism & 5 & 5 & 4 & 14 \\
\hline Industrial Investment & 9 & 9 & 9 & 27 \\
\hline Petrochemical Industries & 3 & 3 & 3 & 9 \\
\hline Retail and Services & 12 & 12 & 12 & 36 \\
\hline Telecommunications & 1 & 1 & 1 & 3 \\
\hline Transportation & 6 & 6 & 6 & 18 \\
\hline Total & 58 & 58 & 49 & 165 \\
\hline
\end{tabular}




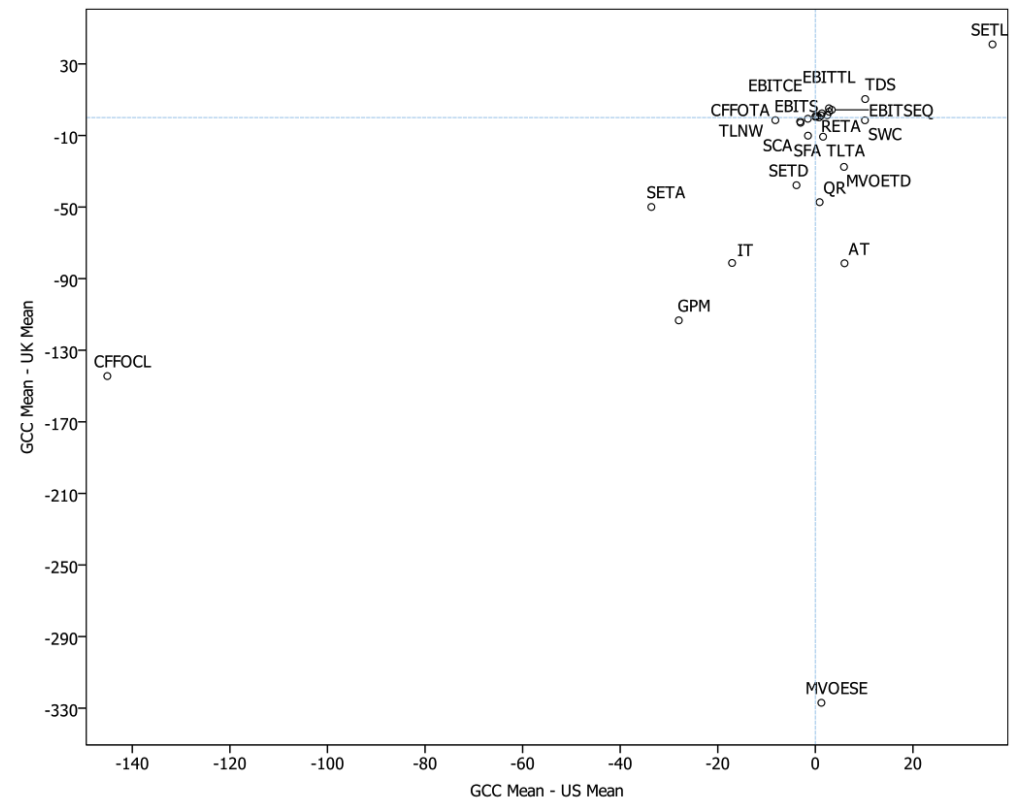

Figure 2 Differences in ratio means: GCC v UK, USA.

1968: Beaver, 1966; Dambolena and Khoury, 2012, Deakin, 1972, Elam, 1975 Gombola and Ketz, 1983a; Mensah, 1983). The 28 include activity, cash flow, leverage, liquidity, market and profitability ratios, and they cover all 6 major categories of ratio. The descriptive statistics of the ratios in each country are presented in Table 2 .

Normality tests showed that none of the 28 ratios are normally distributed in any of the three countries; the Shapiro-Wilks statistic was significant at the $0.001 \mathrm{p}$-value level for all ratios.

Figure 2 is a graph that shows the differences in the mean values of the ratios between the GCC and the UK and USA. For each ratio, we have calculated the differences of GCC mean less the UK mean and the GCC mean less the USA mean. Thus, positive values indicate that the GCC mean is greater than those of the UK or the USA; negative values indicate a lesser mean. In the graph, points close to the vertical axis represent small differences between the GCC and the UK, and points close to the horizontal axis represent small differences 
between the GCC and the USA.

In Figure 2, most of the ratios are located in a cluster around the origin, but a number of ratios show noteworthy mean differences. The largest difference observed is for the mean level of MVOESE, which is much smaller in the GCC than in the UK, unlike the USA where it is of similar magnitude to that of the GCC. The second biggest difference is for the mean value of the ratio CFFOCL it is much smaller in the GCC than in the cases of both the UK and the USA. The leverage ratios SETL and SETA present an interesting contrast, which may suggest important differences in levels of shareholders' equity over liabilities compared to shareholders' equity over assets. SETL has a much larger mean value in the GCC than is the case in both the UK and the USA, whereas the mean for SETA is much smaller than both the UK and the USA. The mean values of GPM (Gross Profit/Sales) and IT (Cost of Sales/Inventory) are also notably smaller in the GCC than they are in both the UK and the USA. Similarly, the mean value of $A T$ (Sales/Total Assets) is much smaller in the GCC than it is in the UK; it is also smaller than in the USA, although not to the same extent. 


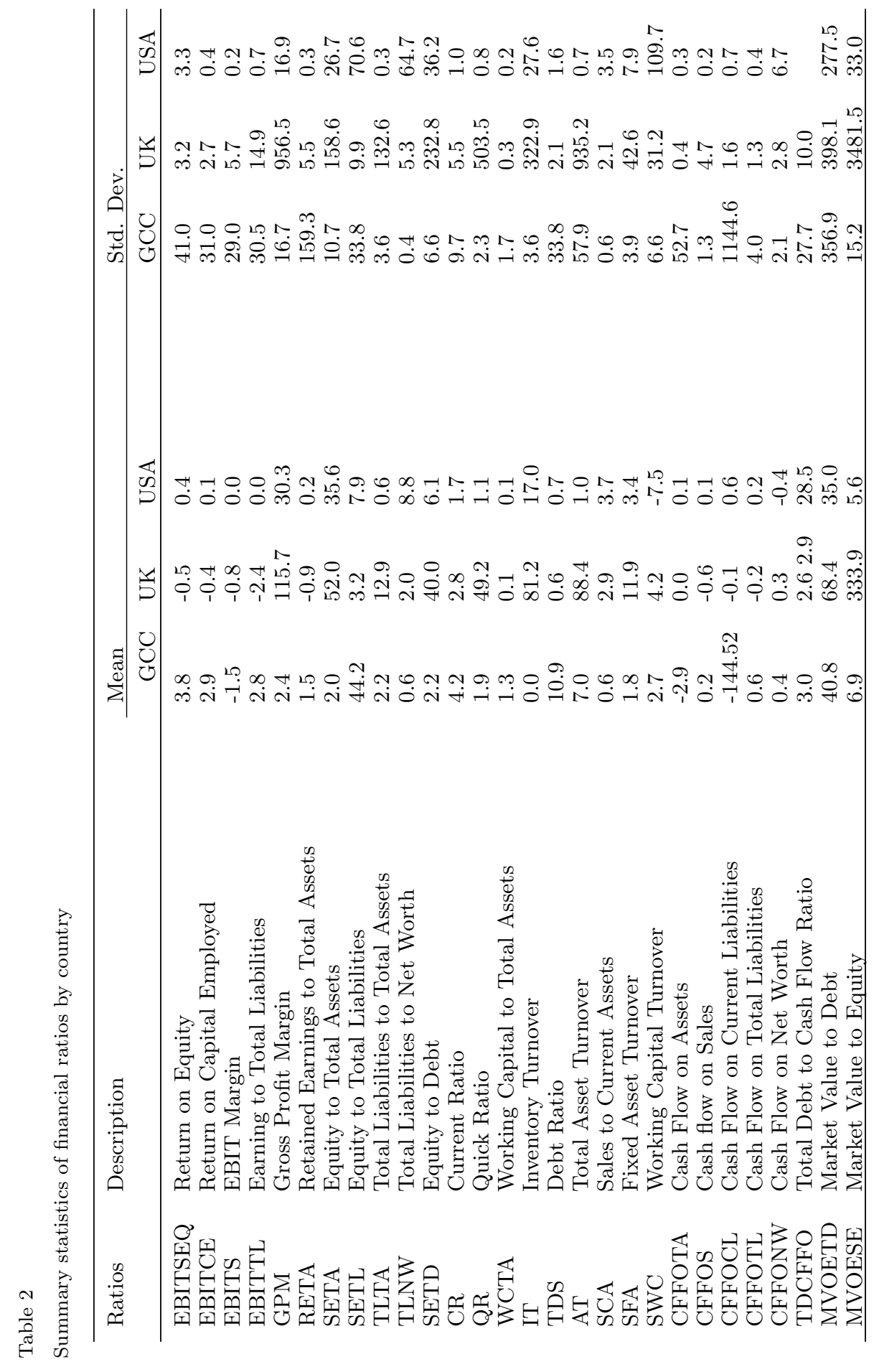


Table 3

Descriptive statistics of macroeconomic variables

\begin{tabular}{lllllllllll}
\hline \multirow{2}{*}{ Factor } & \multicolumn{3}{l}{ Mean } & \multicolumn{4}{c}{ Std. Dev. } & \multicolumn{3}{c}{ Coefficient } \\
\cline { 2 - 11 } & GCC & UK & USA & GCC & UK & USA & & GCC & UK & USA \\
\hline Stock Index & 26.7 & 784.2 & 319.7 & 137.6 & 417.0 & 1137.4 & 26.1 & 15.0 & 15.5 \\
Inflation Rate & 0.3 & 0.9 & 0.5 & 3.1 & 0.9 & 1.4 & 71.4 & 32.7 & 58.3 \\
Interest Rate & 0.4 & 0.5 & 0.4 & 0.9 & 2.1 & 1.5 & 16.9 & 82.3 & 33.0 \\
Oil prices & 6.1 & 1.5 & 9.1 & 26.9 & 30.5 & 30.0 & 31.3 & 37.5 & 33.7 \\
\hline
\end{tabular}

\subsubsection{Measures of macroeconomic conditions}

305

on the inflation rate, interest rate and oil price corresponding to the financial statement year for each pair of firms and the country of the firms. The literature suggests these macro variables may impact insolvency (Desai and Montes, 1982 Goudie and Meeks, 1991; Jayasekera, 2018). We also collected data on the stock level.

\subsection{Data analysis and results: three-way multidimensional scaling}

\subsubsection{Rationale of three-Way MDS}

We used three-way Multidimensional Scaling to address the research ques- 
greatest amount of the structure within a large amount of data using only a few key dimensions. MDS can be conducted with metric or non-metric variables (Kruskal, 1964; Kruskal and Wish, 1978) and, for this reason, it is often preferred over other data reduction techniques, such as factor analysis when all variables of interest are not at least interval scaled or do not satisfy distributional assumptions, such as normality. Typically, MDS involves the construction of a map based on similarities or proximities among data entities (cases or variables) from the given data such that entities with similar characteristics are located near to each other on the map. Hence, the structure within the data can be inferred by studying the loci of known entities on the map. Three-way MDS extends the analysis into a third way by examining data from different sources. Here the idea is that data from different sources can have a common structure (among the cases or variables) but also individual differences due to each source. For this reason, three-way MDS is ideal for our purposes because we can study the similarities among the firms but also the differences due to the source, i.e. type of firm (solvent, insolvent) from a specific country.

There are several advantages that three-way MDS offers, which are relevant to the current research. First, it allows data reduction from many financial ratios to a smaller number of more broad dimensions of financial ratios. This 345 allows us to summarise the structure of the data. Second, the three-way structure allows us to better capture the hierarchical, multilevel structure of the data, allowing study at various levels of analysis. Most importantly in this study, this advantage allows us to examine patterns at sector level. Third, MDS output lends itself very well to visualisation via MDS maps. Visualisation often offers the ability to understand patterns not readily available in other types of output such as tables of statistical output. In our study, the value of the visualisation is enhanced as we have overlaid the maps MDS with the results of the additional, Cluster analysis. We argue that the visualisation is key in explaining the patterns in the financial ratios revealed by the MDS. Finally, MDS is nonparametric. As such, it is suitable for analysing the data even if the data do not obey distributional assumptions such as normality. On the other hand, the 
latter may also be considered a disadvantage of MDS. The lack a parametric basis implies there are no statistical tests associated with MDS that can be used to test hypotheses and then apply conventional p-value based decisions to reject or accept hypotheses. Another limitation, as we discuss below, is that it is necessary to apply discretionary rules to decide the number of dimensions to retain in the final solution. As such the final solution involves a trade-off between parsimony and comprehensive data coverage.

\subsubsection{Number of $M D S$ dimensions to retain} the main objective of MDS is to represent the data structure using a small number of key dimensions, the number of dimensions retained should be much smaller than the number of entities in the data. Typically, it is no more than a handful of MDS dimensions that, like components in Principal Components the majority of the variance in the data; they are the most meaningful and most interpretable. Higher dimensions, which capture less variance, are less important and less meaningful, and, as such, harder to interpret, but the amount of variance explained increases in the number of dimensions retained. Therestudy we adopted a method applied by Neophytou and Mar-Molinero (2004) and Chipulu et al. (2013), where the dimensionality of the data is decided by an independent model a priori to the actual MDS model.

Although PCA differs from CATPCA and MDS in that it is parametric and they are not, the three techniques share a commonality in that their overarching purpose is data reduction. In all three, one starts off with a dataset with many variables, which one then reduces to a smaller number of dimensions (or components). In all three, the number of dimensions to retain can range from the minimum of one to the maximum of $j$, where $j$ is the number of variables how many dimensions (or components) to retain between one and $\mathrm{j}$. There 


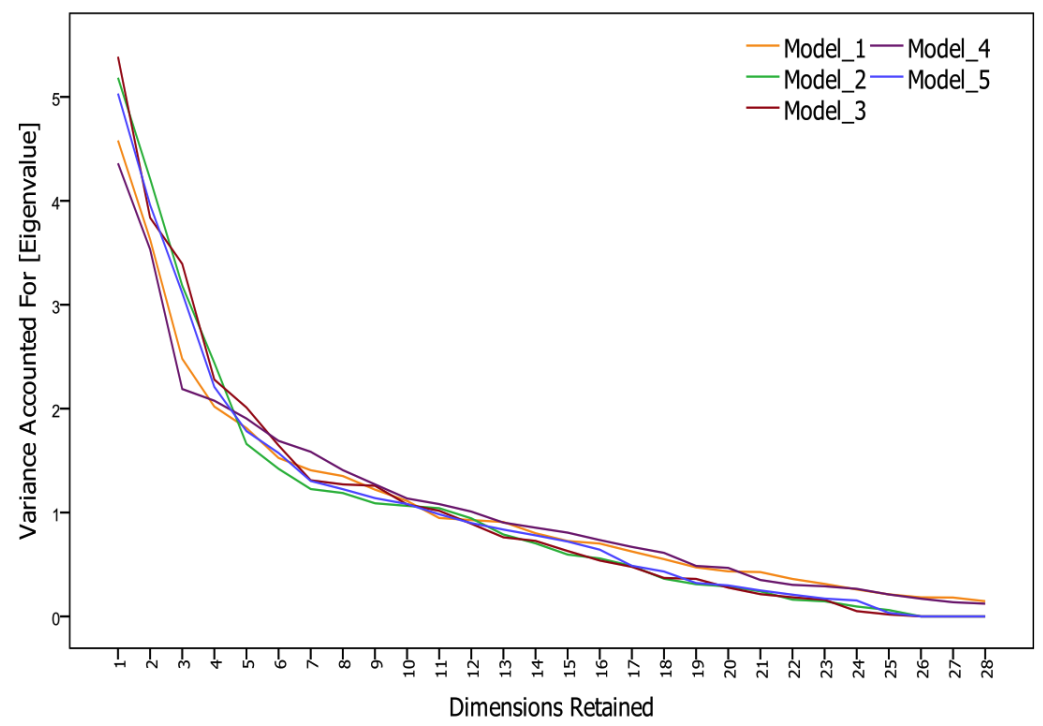

Figure 3

Variance accounted for per dimensions retained

happens to be a lot more research and experience with the application of PCA. From this, researchers have developed discretionary rules for determining the number of dimensions to retain. Since these rules work well and they are applied post-analysis and are, therefore, independent of the parametric basis of PCA, a number of previous research has demonstrated that they also work well for MDS. Hence, it is important to emphasize that it is these discretionary rules developed by PCA researchers that we have borrowed rather than any core part of the PCA technique itself.

395 We sampled the dataset to obtain five bootstrap replicates of it. Each replicate was equal in size to the original dataset. We then conducted categorical principal components analysis (CATPCA) of the 28 ratios for each replicate.

Figure 3 is a scree plot or "elbow diagram" which shows the amount of variance explained by each dimension for each of the five CATPCA models. The overall shape in Figure 3 suggests a turn or "elbow" at Dimension 4: four dimensions may be sufficient to capture the majority of the structure in the data. 
However, the lines in Figure 3 are somewhat divergent, indicating that the exact dimensionality of the data is uncertain. Therefore, adopting a conservative approach commonly used in PCA (Neophytou and Mar-Molinero, 2004), we extracted an MDS configuration with six dimensions, but only interpreted the first four; as we treated the last two dimensions as representing residual variation.

\subsubsection{Three-way MDS procedure}

The first step in the MDS was to split the data into the six data "sources" representing each type of firm in each country, which are "GCC-insolvent", "GCC-Solvent", "UK-Insolvent", "UK-Solvent", "USA-Insolvent" and "USASolvent". For each source, we calculated proximities among the 28 financial ratios using the Euclidean distance metric. As a result, there were six proximity matrices one for each source. We then entered the six matrices as the inputs into the three-way MDS model using the Prefscal algorithm (Busing et al.

415 2005). The Prefscal algorithm first estimated a six-dimensional space common to all sources. Secondly, it rescaled the common space along each of the six dimensions, based on the weight each source places on that dimension. In other words, scale transformations were applied to the common space until the resultant space was a good fit for each individual source.

The final three-way MDS model fitted the data well. It accounted for $82 \%$ of the variance in the ratios, and the normalised stress value was 0.05. The sum-of-squares of DeSarbo's Inter-mixedness Indices was 0.19, and the Shepard's Rough Non-degeneracy Index was 0.76, which indicates that the extracted configuration is unlikely to be degenerate (Busing et al. 2005). Table 4 is a list of the coordinates of each ratio on the four MDS dimensions of interest.

\subsubsection{Hierarchical cluster analysis (HCA) of ratios}

Once again, we followed the precedents set by (Neophytou and Mar-Molinero, 2004) in that we used hierarchical cluster analysis (HCA) to help us interpret the MDS dimensions. We used Ward's method to cluster the 28 ratios based 430 on the Euclidean distances among them. We selected Ward as the clustering 
method because it produces compact clusters by minimising cluster variance (Punj and Stewart, 1983).

Table 4

Coordinates of ratios on retained MDS dimensions

\begin{tabular}{|c|c|c|c|c|c|}
\hline Variable & Variable Description & Dim_1 & Dim_2 & Dim_3 & Dim_4 \\
\hline MVOETD & $\begin{array}{l}\text { Market Value of Equity/Total } \\
\text { Debt }\end{array}$ & -6.642 & 0.6 & 0.704 & -0.379 \\
\hline GPM & Gross Profit/Sales & -.325 & 0.641 & -1.181 & 0.28 \\
\hline SETA & $\begin{array}{l}\text { Shareholders' Equity/Total As- } \\
\text { sets }\end{array}$ & -0.521 & 0.492 & -0.929 & -0.409 \\
\hline EBITS & EBIT/Sales & 1.196 & -1.319 & 0.087 & -0.006 \\
\hline RETA & Retained Earnings/Total Assets & 1.224 & -1.313 & 0.593 & -0.036 \\
\hline TDS & Total Debt/Sales & 1.3 & -1.268 & 0.335 & -0.307 \\
\hline CFFOTA & CFFO/Total Assets & 1.304 & -1.319 & 0.465 & -0.266 \\
\hline CFFOCL & CFFO/Current Liabilities & 1.382 & -1.201 & 0.75 & 0.107 \\
\hline MVOESE & Market Value of Eq- & 0.86 & 0.633 & -0.697 & -0.444 \\
\hline $\mathrm{CR}$ & $\begin{array}{l}\text { uity/Shareholders' Equity } \\
\text { Current Assets/Current Liabili- } \\
\text { ties }\end{array}$ & 1.175 & -0.946 & -0.862 & -0.792 \\
\hline IT & Cost of Sales/Inventory & -0.576 & 0.483 & -1.085 & -1.446 \\
\hline CFFOS & CFFO/Sales & 1.156 & -1.302 & -1.343 & -1.15 \\
\hline WCTA & Working Capital/Total Assets & 1.165 & -1.292 & -1.299 & -1.317 \\
\hline CFFOTL & CFFO/Total Liabilities & 1.15 & -1.307 & -1.332 & -1.345 \\
\hline CFFONW & CFFO/Net Worth & 0.782 & -0.937 & -1.412 & -1.384 \\
\hline SETL & $\begin{array}{l}\text { Shareholders' Equity/Total Lia- } \\
\text { bilities }\end{array}$ & 1.328 & -1.142 & 0.192 & 0.636 \\
\hline EBITCE & EBIT/Capital Employed & 0.897 & -1.305 & -1.29 & 0.906 \\
\hline EBITTL & EBIT/Total Liabilities & 1.046 & -1.323 & -1.297 & 0.894 \\
\hline $\mathrm{SCA}$ & Sales/Current Assets & 0.582 & -0.986 & -1.359 & -1.425 \\
\hline AT & Sales/Total Assets & 1.559 & 0.599 & 0.472 & -1.143 \\
\hline TLTA & Total Liabilities/Total Assets & 1.538 & 0.387 & -1.111 & -1.149 \\
\hline QR & (Current Assets - & 1.464 & 0.542 & -1.299 & -1.279 \\
\hline & Stocks)/Current Liabilities & & & & \\
\hline EBITSEQ & EBIT/Shareholders' Equity & 0.679 & -1.249 & -1.078 & 0.818 \\
\hline TDCFFO & Total Debt/CFFO & -0.191 & -0.952 & 0.246 & -1.54 \\
\hline SFA & Sales/Fixed Assets & 0.346 & -0.844 & -0.996 & -1.42 \\
\hline TLNW & Total Liabilities/Net Worth & -0.401 & -1.091 & -1.411 & -1.489 \\
\hline SWC & Sales/Working Capital & -0.386 & 0.179 & -1.003 & -1.212 \\
\hline SETD & Shareholders' Equity/Total & -0.185 & 0.567 & -0.866 & -0.82 \\
\hline & Debt & & & & \\
\hline
\end{tabular}


There were several stages in the HCA agglomeration schedule. We selected a fivecluster solution which appeared at the fifth stage. This was because we judged it to be

435 1 contains only the ratio MVOESE; Cluster 2 contains only CFFOCL and Cluster 3 contains the activity ratio $A T$ and the profitability ratio GPM. The presence of $A T$ implies efficiency in generating sales from assets; GPM suggests efficiency in generating net revenues after accounting for cost of goods (Megginson and Smart, 2006). This combination, we believe, suggests that Cluster 3 is an indicator of efficiency of sales activities. Cluster 4 contains the three leverage ratios SETD, TLTA and SETA, the liquidity ratio $Q R$, the activity ratio $I T$ and the market ratio MVOETD. It is dominated by ratios which indicate a firm's ability to manage debt in such a way that it can maintain liquidity to finance its activities and accumulate market value, i.e. 445 sustain day-to-day activities while growing in the long term. Therefore, we interpreted Cluster 4 as operational and strategic debt management. Cluster 5 is the largest. It contains 18 ratios, which cover all 6 ratio categories except market. Cluster 5 appears to represent nearly all measures of a firm's financial performance. Therefore, we labelled it as having generic financial performance.

\subsubsection{Meaning of $M D S$ dimensions}

To enable visualisation and, hence, greater ability to see the structure in the data, we drew two-dimensional (2-D) maps of the MDS dimensions of the ratios using the coordinates in Table 4 This mapping approach is typical in MDS; see, for example, Neophytou and Mar-Molinero (2004). Figure 4 is a map of Dimension 1 versus 2, and Figure 5 is a map of Dimension 3 versus 4 . Since the dimensionality of the actual MDS configuration is higher than two, the relative locations of the ratios on the 2-D maps can be misleading.

To help show the true overall distances among the ratios as well as aid interpretation, we added the five HCA clusters as an overlay on the MDS maps. In the same way that one would associate PCA components with high-loading variables, when interpreting each dimension, we paid the most attention to those ratios which have large (in absolute value terms) coordinate values on them; this is because those are the ratios that are most strongly associated with the dimension (see also Chipulu et al. (2013)).

In Table 4, we have highlighted the ratios we have used in this way. We interpreted 
Table 5

The contents of HCA ratio clusters

\begin{tabular}{|c|c|}
\hline \multicolumn{2}{|l|}{ Cluster 1} \\
\hline MVOESE & Market: Market Value to Equity \\
\hline \multicolumn{2}{|l|}{ Cluster 2} \\
\hline CFFOCL & Cash Flow: Cash Flow on Current Liabilities \\
\hline \multicolumn{2}{|l|}{ Cluster 3} \\
\hline AT & Activity: Total Asset Turnover \\
\hline GPM & Profitability: Gross Profit Margin \\
\hline \multicolumn{2}{|l|}{ Cluster 4} \\
\hline MVOETD & Market: Market Value to Debt \\
\hline QR & Liquidity: Quick Ratio \\
\hline IT & Activity: Inventory Turnover \\
\hline SETD & Leverage: Equity to Debt \\
\hline TLTA & Leverage: Total Liabilities to Total Assets \\
\hline SETA & Leverage: Equity to Total Assets \\
\hline \multicolumn{2}{|l|}{ Cluster 5} \\
\hline EBITS & Profitability: EBIT Margin \\
\hline EBITTL & Profitability: Earning to Total Liabilities \\
\hline EBITCE & Profitability: Return on Capital Employed \\
\hline EBITSEQ & Profitability: Return on Equity \\
\hline SETL & Leverage: Equity to Total Liabilities \\
\hline TLNW & Leverage: Total Liabilities to Net Worth \\
\hline RETA & Leverage: Retained Earnings to Total Assets \\
\hline CR & Liquidity: Current Ratio \\
\hline WCTA & Liquidity: Working Capital to Total Assets \\
\hline SFA & Activity: Fixed Asset Turnover \\
\hline TDS & Activity: Debt Ratio \\
\hline $\mathrm{SCA}$ & Activity: Sales to Current Assets \\
\hline SWC & Activity: Working Capital Turnover \\
\hline CFFOTA & Cash Flow: Cash Flow on Assets \\
\hline TDCFFO & Cash Flow: Total Debt to Cash Flow Ratio \\
\hline CFFOS & Cash Flow: Cash flow on Sales \\
\hline CFFOTL & Cash Flow: Cash Flow on Total Liabilities \\
\hline CFFONW & Cash Flow: Cash Flow on Net Worth \\
\hline
\end{tabular}


the four MDS dimensions as follows:

Dimension 1: Effectiveness of sales and cash-generating activities

In Figure 4. Clusters 3, 4 and 5 are all located on both the negative and positive sides of Dimension 1. Therefore, none of the three clusters is, in itself, a clear pointer towards the meaning of Dimension 1. However, one can see that AT (Sales/Total Assets), TLTA (Total Liabilities/Total Assets) and $Q R$ (Current Assets-Stocks)/Current Liabilities) have large, positive coordinates on Dimension 1. $Q R$ reflects a firm's ability to use its liquid assets to meet short-term obligations; $A T$ indicates how efficiently the firm can generate sales from its assets, and TLTA indicates how well the firm uses its creditors' funds to finance activities (Bragg, 2002, Megginson and Smart, 2006). CFFOTA (Cash Flow from Operations/Total Assets), SETL (Shareholders' Equity/Total Liabilities) and CFFOCL (Cash Flow from Operations/Current Liabilities) also have large, positive coordinate values on Dimension 1. We believe this pattern of ratios represents a measure of how well a firm uses its assets and creditors' funds to generate sales and cash, and to maintain liquidity. A high level of cash or liquidity increases capacity to meet debt obligations: this may explain the large, positive coordinate of $T D S$ (Total Debt/Sales). Thus, we interpreted dimension 1 to be an indicator of effectiveness of sales and cash-generating activities.

Dimension 2: Trade-off between debt management and cash generation/profitability

The proximity of Clusters 3 and 4 on the positive side of Dimension 2 in Figure 4 suggests this side of Dimension 2 may represent a firm's effectiveness at managing debt, which may go hand in hand with efficient sales activities. Cluster 5 occupies most of the negative side of Dimension 2. Given the generic nature of Cluster 5, this provides no helpful guide per se. However, by inspecting Table 3, one can see that the ratios with the highest negative coordinates on Dimension 2 are either indicators of profitability, namely EBITS, EBITTL and EBITCE, or cash flow measures, namely CFFOTA, CFFOS and CFFOTL. Hence, we interpreted Dimension 2 to be a trade-off between debt management and cash generation/profitability.

Dimension 3 is similar to Dimension 1 in that the location of the clusters is not very helpful in terms of interpreting the dimensions. Hence, as with Dimension 1, we relied on the ratios with high coordinate values to interpret dimension 3. CFFOCL (Cash 


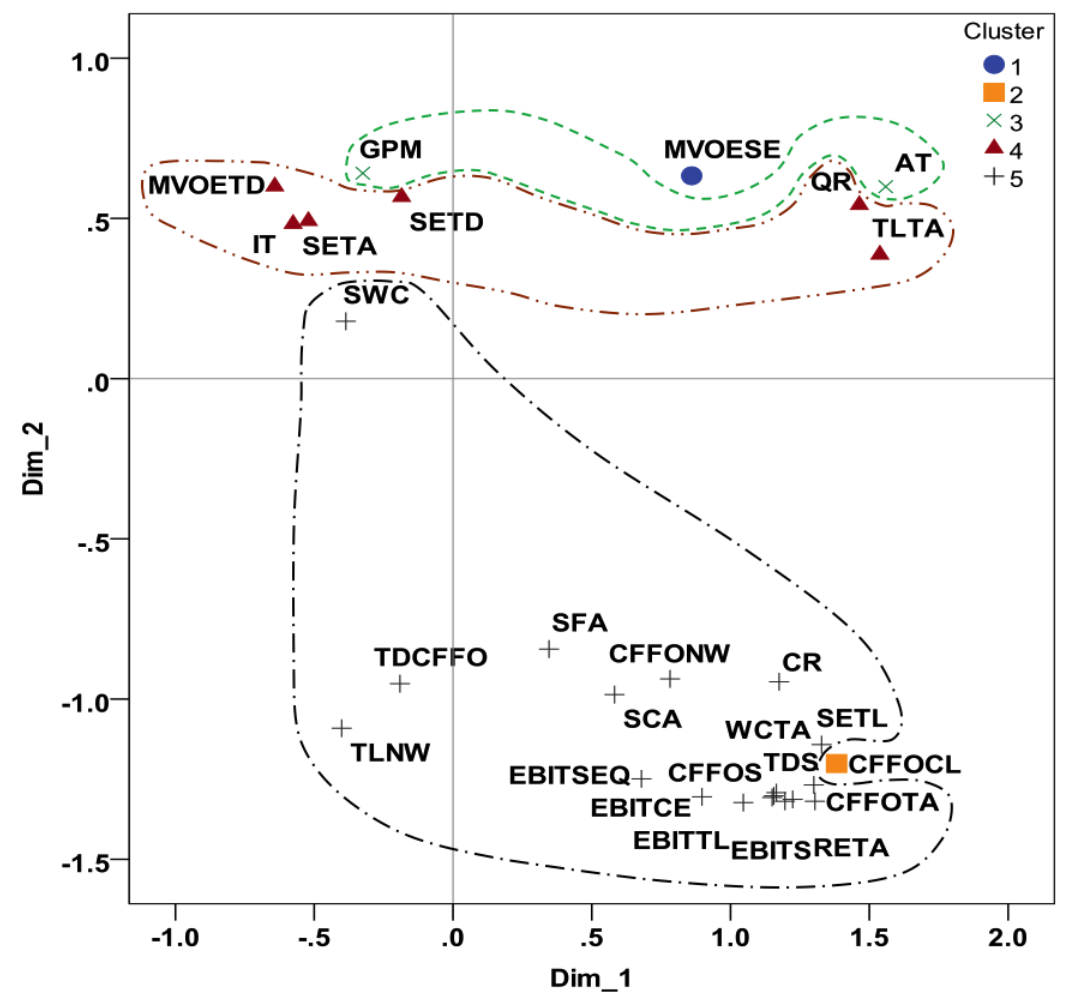

Figure 4 Map of Dimension 1 versus Dimension 2 
Flow from Operations/Current Liabilities) has the largest positive coordinate, followed by MVOETD (Market Value of Equity/Total Debt). Together, these two ratios suggest ability to generate cash and accrue market value from debt. In contrast, the two ratios with the largest negative coordinates CFFONW (Cash Flow from Operations/Net Worth) and $T L N W$ (Total Liabilities/Net Worth) measure how well a firm uses its net worth. Dimension 3 appears to be a contrast between using debt, for example, to earn cash, as opposed to using a firm's own assets, i.e. its net worth. Therefore, we labelled Dimension 3 usage of debt versus usage of own assets.

Dimension 4: Trade-off between profitability and cash-generating activities

As with Dimensions 3 and 1, we interpreted Dimension 4 by looking at the ratios with large coordinates. On the one hand, Dimension 4 appears to be about profitability. The largest positive coordinates are for the profitability ratios EBITCE (Earnings before Interest and Taxes/Capital Employed), EBITTL (Earnings before Interest and Taxes/Total Liabilities) and EBITSEQ (Earnings before Interest and Taxes/Shareholders' Equity). On the other hand, the ratios with the large, negative coordinates are either indicators of cash generation, namely TDCFFO (Total Debt/Cash Flow from Operations), CFFONW (Cash Flow from Operations/Net Worth) and CFFOTL (Cash Flow from Operations/Total Liabilities), or indicators of activity; that is to say, IT (Cost of Sales/Inventory), SCA (Sales/Current Assets) and SFA (Sales/Fixed Assets). We concluded, hence, that dimension 4 is a trade-off between 520 profitability and cash-generating activities. We believe that this interpretation is consistent with the large, negative coordinate value of $T L N W$ (Total Liabilities/Net Worth) on Dimension 4. As a result, highly leveraged firms may be forced to generate large amounts of cash to meet their obligations, even at the expense of profitability.

\subsubsection{Relative importance attached to MDS dimensions}

We can infer the importance that each source attaches to the dimensions by studying the weights or re-scaling factors that are required to transform the common space into an individual space relevant only to each source. Table 6 is a summary of the importance weighting that each source attaches to each dimension and the overall relative importance of each dimension, which is determined by the amount of variance that each dimension accounts for. Table 6 also shows the specificity of each source. As explained by (Khoja et al., 2014, p. 19), an intuitive interpretation of specificity is 


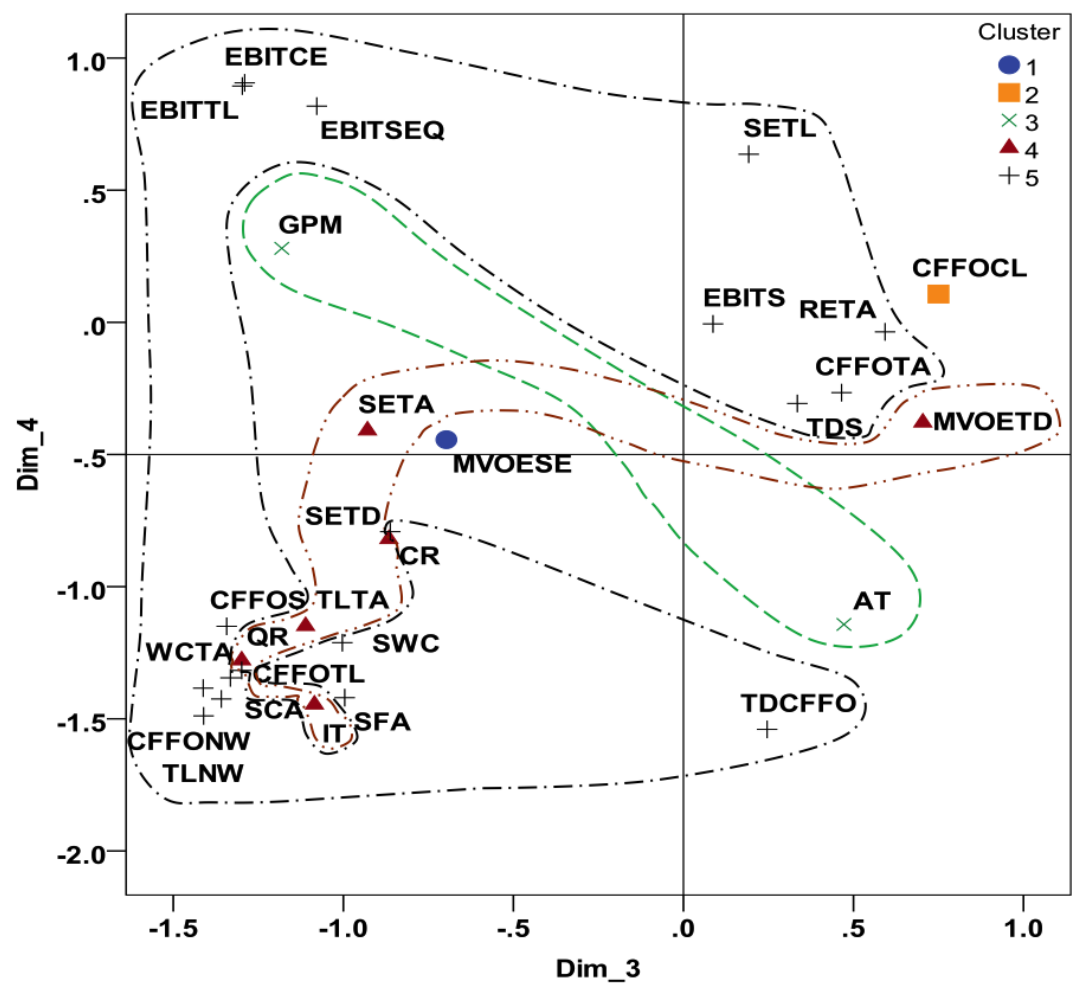

Figure 5 Map of Dimension 3 versus Dimension 4 
Table 6

Importance attached to dimensions by sources

\begin{tabular}{llllll}
\hline \multirow{2}{*}{ Source } & \multicolumn{2}{l}{ Dimensions } & \multirow{2}{*}{ Specificity } \\
\cline { 2 - 5 } & Dim_1 & Dim_2 & Dim_3 & Dim_4 & \\
\hline GCC Insolvent Firm & 3.0 & 18.4 & 1284.4 & 18.3 & $\mathbf{0 . 9}$ \\
GCC Solvent Firm & 1291.3 & 809.2 & 524.9 & 2.8 & $\mathbf{0 . 4}$ \\
UK Insolvent Firm & 1359.7 & 586.2 & 1.4 & 21.4 & $\mathbf{0 . 6}$ \\
UK Solvent Firm & 435.9 & 79.9 & 322.9 & 1288.8 & $\mathbf{0 . 7}$ \\
USA Insolvent Firm & 0.0 & 1400.4 & 0.0 & 0.4 & $\mathbf{1 . 0}$ \\
USA Solvent Firm & 1269.9 & 1010.6 & 331.3 & 313.4 & $\mathbf{0 . 4}$ \\
Importance & $\mathbf{0 . 3 4}$ & $\mathbf{0 . 2 6}$ & $\mathbf{0 . 1 4}$ & $\mathbf{0 . 1 1}$ & \\
\hline
\end{tabular}

that it "captures the trade-off a source makes between focus on one, some or all of the dimensions: as emphasis on one or a few dimensions increases, lack of emphasis on the others may ensue".

We can observe some broad patterns from the data in Table 6 One is that insolvent firms are more specific than solvent firms, which is particularly pronounced in the USA and the GCC, where insolvent firms appear to disregard all but one of the dimensions. Another is that, based how much importance they attach to each dimension, GCC firms resemble USA firms more than UK firms.

The patterns across solvent firms are different. Solvent firms are most alike in their regard for Dimension 3 to which they generally attach moderate weighting. In Dimension 1, solvent firms in the GCC attach about as much weight as those in the USA and more weight than those in the UK. The pattern is somewhat similar in Dimension 2; solvent firms in both the GCC and the USA attach more weight to Dimension 2 than those in the UK but, unlike Dimension 1, the USA weighting is clearly larger than that of the GCC. Solvent firms in the GCC attach much less weight to Dimension 4 than those in the USA and, particularly, the UK.

The results suggest the greatest similarity among solvent firms is that they appear to diversify their efforts; they are not very specific, in that they do not focus on only one, or predominantly one, of the four dimensions while overlooking the others. In terms of how much importance they place on specific dimensions, solvent firms in the GCC, the UK and the USA are most similar in their regard for the third dimension, "usage of debt versus usage of own assets", to which they all ascribe moderate levels of importance. Thus, our results reveal that the solvent companies in the three regions 
by considering a number of financial metrics, i.e. solvency, profitability and operating efficiency. Furthermore, solvent firms have the ability to use assets and debt capital to increase profitability and liquidity, where higher levels of profitability and liquidity with lower levels of leverage indicate decreased risk of insolvency.

560 in the GCC, the UK and the USA attach to the other three dimensions. The USA and GCC are more similar in terms of giving most weight to Dimension 1, "Effectiveness of sales and cash generation activities", as well as Dimension 2, "Trade-off between debt management and cash generation/profitability". This result is not surprising due to and USA. The growth is as a result of increased diversification of USA investments in the GCC, especially in the energy industry, according to Posner and Schmidt (1992). Thus, it is possible to say that the economic and trade integration has had a significant impact on trade and business management in the Gulf countries. Moreover, this clearly provides evidence of the similarly in the managerial styles between GCC and the USA in terms of using and managing their debt. Generally, in recent decades, the GCC region has significantly developed by adopting similar managerial structures to the USA regarding knowledge exchange education.

We can also observe more particular patterns within these broad patterns. In575 solvent firms in the GCC and the USA appear to attach low weight to dimension 1, unlike in the UK, where insolvent firms regard Dimension 1 as having much more weight. Insolvent firms in the GCC attach much less weight to Dimension 2 than those in the USA and, to a lesser extent, the UK. In contrast, insolvent firms in the GCC attach more weight to Dimension 3 than those in the UK and, particularly, the USA. Insolvent firms are most alike in Dimension 4, which they generally regard as being low weight.

Unlike solvent firms, insolvent firms appear to be very specific in the GCC they appear to focus mainly on the "usage of debt versus usage of own assets", while in the USA, they appear to focus only on the "trade-off between debt management and cash generation/profitability". Insolvent firms in the UK, which are the least specific, appear to attach most weight to "effectiveness of sales and cash-generating activities". Thus, although they all equally disregard the fourth dimension, "trade-off 
between profitability and cash-generating activities", the aspects they consider most important, as captured by the MDS dimensions, differ between the GCC, the UK and the USA. The results confirm that insolvent firms face very unique challenges cross countries. In case of insolvent GCC firms, they struggle to generate profit using their own resources; rather, they finance their operations by borrowing and accumulating debts, which increase obviously the probability of the risk insolvency.

There is no consistent pattern in the weight differentials between insolvent and solvent firms. In this respect, UK and USA firms are more similar to each other than they are to GCC firms. The patterns of differences in weights in Dimensions 2, 3 and 4 are the same across the USA and the UK two countries: insolvent firms place more weight on Dimension 2 and less on both dimensions 3 and 4 than solvent firms do. This is the opposite to the GCC, as, in the GCC, insolvent firms place less weight on Dimension 2 and more on both Dimensions 3 and 4. The exception is Dimension 1, which is regarded with more weight by insolvent firms than solvent ones in the UK, whereas the opposite is true in both the GCC and the USA. As such, while the GCC shares this one similarity with the USA in weight differentials, it does not share any similarity with the UK in any of the dimensions.

We can conclude, as Khoja et al. (2014) did, that insolvent firms are much more specific than solvent firms. This shows the low level of the efficiency of operations and investment quality. It also appears that they have difficulty in managing assets to generate a profit. In terms of the polarity of differences, i.e. whether insolvent firms regard a particular dimension to have more weight than solvent firms do, or vice versa, the GCC appears to have very little in common with the USA and, in particular, with the UK.

\subsubsection{Property fitting: relationship of macroeconomic conditions with MDS di- mensions}

The final step in the analysis was to examine the effects of macroeconomic variables on the four MDS dimensions. We did so using Property fitting, or Pro-fit. Pro-fit is a method for fitting independent properties to the MDS configuration once it has been extracted, i.e. post-optimally. Typically, Pro-fit involves analysing how independent properties of interest are related to the MDS dimensions using correlation or regression analysis (see, for example, (Mar-Molinero and Mingers, 2006, Schiffman et al., 1981). 
Table 7

Correlations of macroeconomic variables with MDS dimensions

\begin{tabular}{llllll}
\hline \multirow{2}{*}{ Macro Factor } & Statistics & \multicolumn{2}{c}{ Dimensions } \\
\cline { 3 - 6 } & & Dim_1 & Dim_2 & Dim_3 & Dim_4 \\
\hline \multirow{2}{*}{ Stock Index } & Coefficient & -0.571 & 0.193 & -0.236 & -0.18 \\
& p-value & 0.00 & 0.149 & 0.079 & 0.179 \\
Inflation Rate & Coefficient & 0.435 & -0.316 & 0.135 & 0.18 \\
& p-value & 0.001 & 0.019 & 0.313 & 0.179 \\
Interest Rate & Coefficient & 0.582 & -0.257 & 0.151 & 0.18 \\
\multirow{3}{*}{ Oil Price } & p-value & 0.00 & 0.055 & 0.26 & 0.179 \\
& Coefficient & 0.207 & -0.199 & 0.045 & 0.005 \\
& p-value & 0.123 & 0.138 & 0.737 & 0.968 \\
\hline
\end{tabular}
each macroeconomic variable and each financial ratio using Kendall's Tau-b correlation coefficient. We chose Kendall's Tau-b because it is non-parametric and, therefore, suitable for the data which are non-normal. Secondly, we calculated the correlation (also using Kendall's Tau-b) between each macroeconomic variable and each of the MDS dimensions. We based this calculation on the proximity value for each ratio calculated in the first step and the coordinate value for that ratio on that MDS dimension (Table 4).

The results presented in Table 7 indicate that Dimension 1, which we believe indicates the "effectiveness of sales and cash-generating activities", is positively related to inflation and interest rates and negatively to the stock index. Dimension 2, which we interpreted as the "trade-off between debt management and cash generation/profitability", is negatively related to the inflation rate. The other two dimensions do not appear to be significantly related to any of the macroeconomic variables. The results also show that the price of oil is not related to any of the ratio dimensions.

Consistent with other studies (Rose et al., 1982, Young, 1995), we found significant relationships between the dimensions of ratios and the macroeconomic variables. The results suggest that inflation, interest rates and the stock index are significantly related to Dimension 1, "effectiveness of sales and cash generating activities". Inflation is also related to Dimension 2, "trade-off between debt management and cash generation/profitability". Since neither insolvent firms in the GCC nor those in the USA consider dimension 1 as important, the observed correlations imply, by overlooking 
Dimension 1, that insolvent firms in the GCC and the USA may also be overlooking the macroeconomic factors which are associated with Dimension 1.

Additionally, we tested whether the differences in the sector weights on each dimension are statistically significant. Using bootstrapping, we took 100 samples of the data, each sample being of equal size to the original dataset. We then conducted three-way MDS on each sample. This produced 100 samples of sector weights for each dimension. To analyse differences among sector weights, for each dimension, we conducted One-Way Analysis of Variance (ANOVA) with the weight as dependent variable and sector as independent in SPSS 25. The ANOVA results showed that all the F-values were high, with all p-values less than 0.0001 .

\section{Conclusion and Implications}

In this paper, we addressed the issue of characterising corporate financial distress in different contexts, using three-way multidimensional scaling with cluster analysis combined with property fitting. In this respect, the study contributes to the corporate insolvency literature by proposing an in-depth and novel analysis for exploring the role not only of financial ratios in financial distress but also of macroeconomic indicators and industrial information in different dynamic environments. In addition, unlike the distress studies, this study increases the pool of evidence regarding the character of insolvency in a variety of contexts.

As is typically the case in corporate insolvency research, this study suffers from a limited population of failed firms to draw upon. However, it did produce three main original findings and associated implications: First, our findings offer an important additional explanation for the roles of macroeconomic developments, represented by inflation, interest rates and stock market liquidity, in financial distress. Second, our MDS results provide strong evidence for the similarity of the solvent firms in three different regions in terms of their ability to coordinate short- and long-term financial stability plans and their survivability despite the surrounding external economic pressures. Third, our results reveal that insolvent firms face individual difficulties across nations. Overall, our results suggest that differences (or similarities) between firms in the GCC and those in the UK and the USA are much more nuanced than straightforward. This has one clear implication for creditors, investors and competitors, as applying findings from, or applying models calibrated in, the USA or the UK to the 
GCC is likely to produce misleading conclusions. The financial health of firms should be examined in situ within the local macro environment. There is also a clear implication for managers of firms, as concentrating attention on one aspect of financial performance appears to increase the risk of insolvency. The results also suggest that specificity extends to the given macro environment; we cannot assume that the aspects which are most symptomatic of insolvency in the UK or the USA will be reliable identifiers of insolvency in the GCC.

An interesting future direction for this research would be to expand analysis to the financial distress in cases of multinational corporations in different sectors by using complex network approaches. Multinational companies have a complex pattern in terms of responding to extreme events in host counties. This research strives to determine whether the negative impact of economic conditions and extreme events (e.g., natural disasters, man-made disasters, financial and economic crises) in the host countries has been greater for multinational corporations compared with domestic companies.

\section{References}

A. Aziz, D.E., Lawson, G., 1988. Bankruptcy prediction - an investigation of cash flow based models. Journal of Management Studies 25, 419-437.

AlAjmi, J., Kim, J.H., 2012. Are gulf stock markets efficient? evidence from new multiple variance ratio tests. Applied Economics 44, 1737-1747.

Altman, E., 1968. Financial ratios, discriminant analysis and the prediction of corporate bankruptcy. The Journal of finance 23, 589-609.

Altman, E., Narayanan, P., 1997. An international survey of business failure classification models. Financial Markets, Institutions and Instruments 6, 1-57.

Arouri, M., Lahiani, A., , Nguyen, D., 2011. Return and volatility transmission between world oil prices and stock markets of the gcc countries. Economic Modelling $28,1815-1825$.

Aziz, A., Lawson, G., 1989. Cash flow reporting and financial distress models: Testing of hypotheses. Financial Management 18, 55-63. 
Back, B., Laitinen, T., Sere, K., 1996. Neural networks and genetic algorithms for bankruptcy predictions. Expert Systems with Applications 11, 407-413.

Beaver, W., 1966. Financial ratios as predictors of failure. Journal of Accounting Research 4, 71-111.

Bhattacharjee, A., Higson, C., Holly, S., Kattuman, P., 2004. Business failure in uk and us quoted firms: Impact of macroeconomic instability and the role of legal institutions. Cambridge Working Papers in Economics (CWPE).

Booth, P., 1983. Decomposition measures and the prediction of financial failure. Journal of Business Finance and Accounting 10, 67-82.

Bragg, S., 2002. Business ratios and formulas: A comprehensive guide. Wiley.

Busing, F., Groenen, P., Heiser, W., 2005. Avoiding degeneracy in multidimensional unfolding by penalizing on the coefficient of variation. Psycometrika 70, 71-98.

715 Campbell, N., Heriot, K., Jauregui, A., Mitchell, D., 2012. Which state policies lead to us firm exits? analysis with the economic freedom index. Journal of Small Business Management 50, 87-104.

Caves, R., 1998. Industrial organization and new findings on the turnover and mobility of firms. Journal of economic literature 36, 1947-1982.

Charitou, A., Neophytou, E., Charalambou, C., 2004. Predicting corporate failure: Empirical evidence for the uk. European Accounting Review 13, 465-497.

Chipulu, M., Neoh, J., Ojiako, U., Williams, T., 2013. A multidimensional analysis of project manager competences. IEEE Transactions on Engineering Management 60, $506-517$.

Coats, P., Fant, L., 1993. Recognizing financial distress patterns using a neural network tool. Financial Management 22, 142-155.

Dambolena, I., Khoury, S., 2012. Ratio stability and corporate failure. The Journal of finance $35,1017-1026$.

Deakin, E., 1972. A discriminant analysis of predictors of business failure. Journal of 730 Accounting Research 10, 167-179. 
Desai, M., Montes, A., 1982. A macroeconomic model of bankruptcies in the british economy. British Review of Economic Issues 4, 1-14.

Elam, R., 1975. The effect of lease data on the predictive ability of financial ratios. The Accounting Review 50, 25-43.

735 Ezzamel, M., Molinero, C.M., Beech, A., 1987. On the distributional properties of financial ratios. Journal of Business Finance and Accounting 14, 463-481.

Fabozzi, F., Gupta, F., Markowitz, H., 2002. The legacy of modern portfolio theory. The Journal of Investing 11, 7-22.

Firth, D., 1993. Bias reduction of maximum likelihood estimates. Biometrika 80, $27-38$.

Gilbert, L., Menon, K., Schwartz, K., 1990. Predicting bankruptcy for firms in financial distress. Journal of Business Finance and Accounting 17, 161-171.

Gombola, M., Ketz, J., 1983a. Financial ratio patterns in retail and manufacturing organizations. Financial Management 12, 45-56.

Gombola, M., Ketz, J., 1983b. A note on cash flow and classification patterns of financial ratios. The Accounting Review 58, 105-114.

Goudie, A., Meeks, G., 1991. The exchange rate and company failure in a macro-micro model of the uk company sector. The Economic Journal 101, 444-457.

Gupta, M., Huefner, R., 1972. A cluster analysis study of financial ratios and industry characteristics. Journal of Accounting Research 10, 77-95.

Hossari, G., 2009. Absence of industry effect in modelling corporate collapse in australia. Global economy and finance journal 2, 20-30.

Jayasekera, R., 2018. Prediction of company failure: Past, present and promising directions for the future. International Review of Financial Analysis 55, 196-208.

755 Jones, S., Hensher, D., 2004. Predicting firm financial distress: A mixed logit model. The Accounting Review 79, 1011-1038. 
Khoja, L., Chipulu, M., Jayasekera, R., 2014. Analysing corporate insolvency in the gulf cooperation council using logistic regression and multidimensional scaling. Review of Quantitative Finance and Accounting 46, 483518.

Kozlowski, S., Klein, K., 2000. A multilevel approach to theory and research in organizations. Academy of Management Review 31.

Kruskal, J., 1964. Multidimensional scaling by optimizing goodness of fit to a nonmetric hypothesis. Psychometrika 29, 1-27.

Kruskal, J., Wish, M., 1978. Multidimensional scaling. Quantitative Applications in the Social Sciences, SAGE.

Kumar, P.R., Ravi, V., 2007. Bankruptcy prediction in banks and firms via statistical and intelligent techniquesa review. European Journal of Operational Research 180, $1-28$.

Liu, J., 2004. Macroeconomic determinants of corporate failures: Evidence from the uk. Applied Economics 36, 939-945.

Mar-Molinero, C., Mingers, J., 2006. An evaluation of the limitations of, and alternatives to, the co-plot methodology. Journal of the Operational Research Society 58, $874-886$.

Megginson, W., Smart, S., 2006. Introduction to corporate finance. Mason.

Mensah, Y., 1983. The differential bankruptcy predictive ability of specific price level adjustments: Some empirical evidence. Accounting Review 58, 228-246.

Molinero, C.M., Ezzamel, M., 1991. Multidimensional scaling applied to corporate failure. Omega 19, 259-274.

Morris, R., 1997. Early warning indicators of corporate failure: A critical review of previous research and further empirical evidence. Ashgate.

Mselmi, N., Lahiani, A., Hamza, T., 2017. Financial distress prediction: The case of french small and medium-sized firms. International Review of Financial Analysis $50,67-80$. 
Neophytou, E., Mar-Molinero, C., 2004. Predicting corporate failure in the uk: A multidimensional scaling approach. Journal of Business Financial Accounting 31, $677-710$.

Ohlson, J., 1980. Financial ratios and the probabilistic prediction of bankruptcy. Journal of Accounting Research 18, 109-131.

Peel, M., Peel, D., Pope, P., 1986. Predicting corporate failuresome results for the uk corporate sector. Omega 14, 5-12.

Platt, H., Platt, M., 1991. A note on the use of industry-relative ratios in bankruptcy prediction. Journal of Banking and Finance 15, 1183-1194.

Platt, H., Platt, M., Pedersen, J., 1994. Bankruptcy discrimination with real variables. Journal of Business Finance and Accounting 21, 491-510.

Posner, B., Schmidt, W.H., 1992. Values and the american manager: An update updated. California Management Review 34, 80-94.

Punj, G., Stewart, D., 1983. Cluster analysis in marketing research: Review and suggestions for application. Journal of Marketing Research 20, 134-148.

Ravisankar, P., Ravi, V., Bose, I., 2010. Failure prediction of dotcom companies using neural networkgenetic programming hybrids. European Journal of Operational Research 180, 1257-1267.

Rose, P., Andrews, W., Giroux, G., 1982. Predicting business failure: A macroeconomic perspective. Journal of Accounting, Auditing and Finance 6, 20-31.

Salchenberger, L., Cinar, E., Lash, N., 1992. Neural networks: A new tool for predicting thrift failures. Decision Science 23, 899-916.

Schiffman, S., Reynolds, M., Young, F., 1981. Introduction to multidimensional scaling theory and methods and applications. Emerald.

Scott, J., 1981. The probability of bankruptcy: A comparison of empirical predictions and theoretical models. Journal of Banking and Finance 5, 317-344.

Shin, K., Lee, Y., 2002. A genetic algorithm application in bankruptcy prediction modeling. Expert Systems with Applications 23, 321-328. 
Sung, T., Chang, N., Lee, G., 1999. Dynamics of modeling in data mining: Interpretive approach to bankruptcy prediction. Journal of Management Information Systems $16,63-85$.

815 Tinocoa, M., N., H.P.W., 2018. Polytomous response financial distress models: The role of accounting, market and macroeconomic variables. International Review of Financial Analysis 59, 276-289.

Tinocoa, M., N., W., 2013. Financial distress and bankruptcy prediction among listed companies using accounting, market and macroeconomic variables. International Review of Financial Analysis 30, 394-419.

Varetto, F., 1998. Genetic algorithms applications in the analysis of insolvency risk. Journal of Banking and Finance 22, 1421-1439.

Wadhwani, S., 1986. Inflation, bankruptcy, default premia and the stock market. The Economic Journal 96, 120-138.

Young, G., 1995. Company liquidations, interest rates and debt. Manchester School of Economic and Social Studies 63, 57-69.

Zavgren, C., 1985. Assessing the vulnerability to failure of american industrial firms: A logistic analysis. Journal of Business Finance and Accounting 12, 19-45.

Zmijewski, M., 1984. Methodological issues related to the estimation of financial distress prediction models. Journal of Accounting Research 22, 59-82. 